\title{
Characterization of Single Wall Carbon Nanotubes and Activated Carbon with Water Adsorption in Finite-Length Pore Models
}

\author{
Atichat Wongkoblap ${ }^{1, a}$, Chaiyot Tangsathitkulchai ${ }^{1, \mathrm{~b}}$, Nikom Klomkliang, ${ }^{1, \mathrm{c}}$, \\ Duong D. Do $^{2, \mathrm{~d}}$, and Yuvarat Ngernyen ${ }^{3, \mathrm{e}}$
}

1 School of Chemical Engineering, Institute of Engineering, Suranaree University of Technology, Nakhon Ratchasima, Thailand 30000

2 School of Chemical Engineering, University of Queensland, St Lucia, Queensland, Australia, 4072

3 Department of Chemical Engineering, Faculty of Engineering, Khon Kaen University, Khon Kaen, Thailand 40002

E-mail: aatichat@sut.ac.th (Corresponding author), bchaiyot@sut.ac.th, cnikom_b4402954@yahoo.com, dd.d.do@uq.edu.au, enyuvarat@kku.ac.th

\begin{abstract}
Grand Canonical Monte Carlo simulation is used to study water adsorption in activated carbon (AC) and carbon nanotubes (CNT) which is modelled as a bundle of seven tubes, and the simulation results are compared with the experimental data. To investigate the role of functional groups on water adsorption, hydroxyl groups are grafted at various locations on the surface of AC and CNT. For carbon nanotubes, the spacing between tubes can affect the isotherm. For small spacing and functional groups are located on the exterior surface of the central tube, the isotherm is not affected by the spacing and the concentration of the functional group. This is simply due to the geometrical constraint that prevents water to adsorb in the interstices between the tubes. However, the onset of adsorption occurs at lower pressures when the functional group is positioned in the larger interstices. When the spacing is larger, water clusters are readily formed around the functional group, resulting in an enhancement in adsorption, and pore-filling occurs in the interstices. For AC which is modelled as slit pores, the position and amount of functional group affect adsorption. The effects of temperature were also studied, and we observed an unusual behaviour in that the adsorptive capacity at $10{ }^{\circ} \mathrm{C}$ is lower than that at $15{ }^{\circ} \mathrm{C}$ which is confirmed with our computer simulation.
\end{abstract}

Keywords: Adsorption, activated carbon, carbon nanotubes, functional group, Monte Carlo simulation, water.

ENGINEERING JOURNAL Volume 17 Issue 4

Received 25 December 2012

Accepted 6 May 2013

Published 1 October 2013

Online at http://www.engj.org/

DOI:10.4186/ej.2013.17.4.93 


\section{Introduction}

Adsorption phenomena in activated carbon (AC) are increasingly studied with molecular simulation, among which Molecular Dynamics (MD) and Monte Carlo (MC) [1-2], are widely used. AC represents an important group of adsorbents because of its large micropore volumes and high surface area. It contains pores of different sizes and shapes. For the simplicity of modeling, AC is assumed to compose of graphitic slit pores of different sizes and early modeling treated these pores having infinite length in extent [3-8]. Since pores in AC are spaces between graphitic crystallites of finite size [9], such an assumption of infinite length does not give a good representation. To this end, there is a trend in recent years to model pores of finite length [10-12] as the desorption branch of a simulated isotherm agrees better with experimental data. We adopted the same approach in this paper, and in addition to the consideration of finite length we also considered functional groups as it is known that they have an important role in the adsorption and desorption of associating fluids, such as water [13].

Single walled carbon nanotubes (SWNTs) have been increasingly used in many applications, for example the energy storage for hydrogen, methane, sensor technology and medical technology [14] since the discovery of carbon nanotube by Iijima in 1991 [15]. SWNTs form bundles due to the strong van der Waals interactions [16], and as a result adsorption can occur at the cusp interstices (between tubes), where the fluid-solid interaction is very strong because of the overlapping of potentials [17]. Isolated single nanotubes have been commonly studied in the literature [14, 17-18], but the results do not describe correctly the experimental data. To develop a better solid model, we model SWNTs as a bundle of seven tubes of finite-length, arranged in a hexagonal pattern [19].

For proper utilization of either AC or SWNT, they must be characterized for structural properties and surface chemistry. For the former, adsorption of nitrogen or argon at their respective boiling points is commonly used. As alternative to these common molecular probes, we believe water could also be used and it is more economical because adsorption of water can be carried out at ambient temperature while argon and nitrogen are used under cryogenic conditions. However the limitation of using water lies in the fact that water does not fill mesopores, and therefore its use is limited to the determination of micropores. Since ACs are mainly microporous, the use of water for characterization should be established and validated with a wide range of microporous samples. While adsorption of non-polar gases, such as argon, and weakly polar gases, such as nitrogen, is well studied both theoretically and experimentally [10], water adsorption exhibits a different behavior because of the strong adsorbate-adsorbate interactions (hydrogen bonding) [19]. For a carbon surface, the interaction between a water molecule and a graphene surface is much weaker than the intermolecular interaction of water, and therefore water adsorption in porous carbon only occurs when its surfaces contain functional groups. Therefore, the aim of this paper is to use graphitic slit pores with functional groups to model AC and bundles of SWNT with functional group to investigate the mechanism of water adsorption, and the isotherms obtained for different pore sizes are then used as a kernel to determine micropore size distributions of ACs and SWNTs.

Molecular simulation has been applied to elucidate the adsorption mechanism of water in hydrophobic SWNTs $[7,14,17,20]$ and carbon slit pores [4-7, 21-24], and comparison between the simulation results and the experimental data has been made $[5,19,22]$. To model water, there are broadly two classes of potential models. One is the point charge models, for example SPC [25], SPCE [26] and ST2 [27] models, while the other is the square-well site models such as the Primitive model (PM) [28] and Müller et al. [4-5] models. In our simulation, we chose the SPCE and the Muller et al's model to represent these two classes. The SPCE model involves long-range Coulombic interactions, and to minimize the cut-off error large simulation box is required. This adds to the high computation cost [21]. The Müller et al.'s model, on the other hand, can mimic the hydrogen bonding without the need for a large simulation box, which reduce the computation time significantly [5], and most importantly this model compares well with the SPCE in the description of water adsorption in slit and cylindrical pores [21, 23].

Most experimental data of water adsorption on activated carbon [29] show Type V isotherm [30] with steep adsorption and desorption branches in the range of reduced pressure from 0.3 to 0.8 [23] and a significant hysteresis loop [29, 31]. Simulated isotherms of water adsorption in graphitic slit pores with no functional group show a vertical pore filling at $\mathrm{P} / \mathrm{P}_{0}$ greater than unity and a much larger hysteresis loop than experimental data [21-23]. The common reason used to explain the difference is the absence of functional groups in the solid models [21-23, 29]; however other factors such as pore length and pore morphology could also contribute to this difference. 


\section{Methodology}

\subsection{Water Model}

The Müller et al. model treats water molecule as one LJ-dispersive site (oxygen atom) at the centre of a tetrahedron and four associating sites, modelled with a square well (SW) potential, placed at the vertices. These four sites represent two hydrogen atoms and two lone pairs of electrons. The molecular parameters are listed in Table 1. The energy well depth for unlike sites (a hydrogen atom of one molecule and a lone pair of electrons of another molecule to form hydrogen bond (HB)) is $\varepsilon_{\mathrm{HB}}$ while that for the like sites is zero. A cut-off radius in the calculation of interaction energy is five times the collision diameter of oxygen atom (500O), and the long range correction is not considered. Details of this model can be found in [4]. SPCE model consists of an LJ site located at the centre of the oxygen atom and three partial charges: a negative charge is located at the LJ site and two positive charges are located along the oxygen-hydrogen bonds. The molecular parameters of the SPCE water model are listed in Table 2 [26].

Table 1. Molecular parameters for the Müller et al. water model [4], where $\varepsilon_{O O}$ and $\sigma_{O O}$ are the energy well depth and the collision diameter of the dispersive site, respectively, $\mathrm{k}$ is the Boltzmann's constant, and $\mathrm{r}_{\mathrm{OH}}$ is the distance between a square well (SW) associating site and the oxygen atom, $\sigma_{\mathrm{HB}}$ is the diameter of the associating site to form hydrogen bond (HB) and $\varepsilon_{\mathrm{HB}}$ is the energy well depth for unlike sites to form hydrogen bond.

\begin{tabular}{lccccr}
\hline Fluid & $\sigma_{\mathrm{OOO}}, \AA$ & $\varepsilon_{\mathrm{Oo}} / \mathbf{k}, \mathbf{K}$ & $\mathrm{roH}_{\mathrm{OH}} \AA$ & $\sigma_{\mathrm{HB}}, \AA$ & $\varepsilon_{\mathrm{HB}} / \mathbf{k}, \mathbf{K}$ \\
\hline $\mathrm{H}_{2} \mathrm{O}$ & $\mathbf{3 . 0 6}$ & 90.0 & 1.2852 & 0.612 & 3800 \\
\hline
\end{tabular}

Table 2. Molecular parameters for the SPCE water model [26], where $\varepsilon_{f f}$ and $\sigma_{f f}$ are the energy well depth and the collision diameter of fluid, respectively and $\mathrm{k}$ is the Boltzmann's constant, $r_{O H}$ is the distance between oxygen and hydrogen atoms, $\theta_{\mathrm{HOH}}$ is the bond angle of water molecule, qo and $\mathrm{qH}_{\mathrm{H}}$ are the negative charge at oxygen atom and the positive charges at hydrogen atoms of water model, respectively.

\begin{tabular}{lcccccr}
\hline Fluid & $\boldsymbol{\sigma}_{\mathrm{ff}}, \AA$ & $\boldsymbol{\varepsilon}_{\mathrm{ff}} / \mathbf{k}, \mathbf{K}$ & $\mathbf{r O H}_{\mathbf{H}} \AA$ & $\boldsymbol{\theta}_{\mathrm{HOH}}$ & qo, e & qH, e \\
\hline $\mathrm{H}_{2} \mathrm{O}$ & 3.166 & 78.23 & 1.00 & 109.47 & -0.8476 & +0.4238 \\
\hline
\end{tabular}

In the case of Müller et al. water model, if A represents a hydrogen atom on one water molecule and B is a lone pair of electrons on another water molecule, the interaction potential energy between A and B to form a hydrogen bond is [4].

$$
\varphi_{\mathrm{HB}}\left(\mathrm{r}_{\mathrm{AB}}\right)=\left\{\begin{array}{cc}
-\varepsilon_{\mathrm{HB}} & \mathrm{r}_{\mathrm{AB}}<\sigma_{\mathrm{HB}} \\
0 & \text { otherwise }
\end{array}\right.
$$

where $r_{A B}$ is the distance between $\mathrm{A}$ and $\mathrm{B}$. In this study, the long-range interactions are not taken into account. For SPCE water model, the interaction between two charges of two different molecules, takes the form of a Coulomb law of electrostatic interaction.

\subsection{Solid Model and Functional Group Model}

We modeled AC with a finite length slit whose walls consist of three graphene layers with an interlayer spacing $(\Delta)$ of $3.354 \AA$. The pore widths used in this study are 10,16, 20 and $30 \AA$, chosen to represent the micropore range and the low end of the mesopore range. For carbon nanotube, we model it with seven tubes arranged in a hexagonal pattern. Figure 1 shows a schematic diagram of bundles of seven tubes in the simulation box and its replica. The pore wall of each tube consists of one graphene layer, and the size (D) of a tube is defined as the diameter of a ring passing through the centers of the carbon atoms forming the 
wall. The separation spacing $(s)$ between two adjacent tubes is defined as the minimum distance between the two adjacent tubes. In the tube bundle, there are two types of interstices: (i) the cusp interstices, and (ii) the square interstices (Fig. 1). The tubes used are (7:7), (8:8), (10:10), and (12:12) SWNTs, which correspond to diameters of $9.5,10.8,13.6$, and $16.3 \AA$, respectively and the spacing, $s$, is varied from 4 to $10 \AA$.

The LJ parameters for a carbon atom in a graphene layer are $\sigma_{\mathrm{ss}}$ and $\varepsilon_{\mathrm{ss}} / \mathrm{k}, 3.4 \AA$ and $28 \mathrm{~K}$, respectively. The LJ interaction energy between a fluid molecule and a carbon atom is calculated with Lennard-Jones 12 6 equation and the cross molecular parameters are calculated from the Lorentz-Berthelot rule.

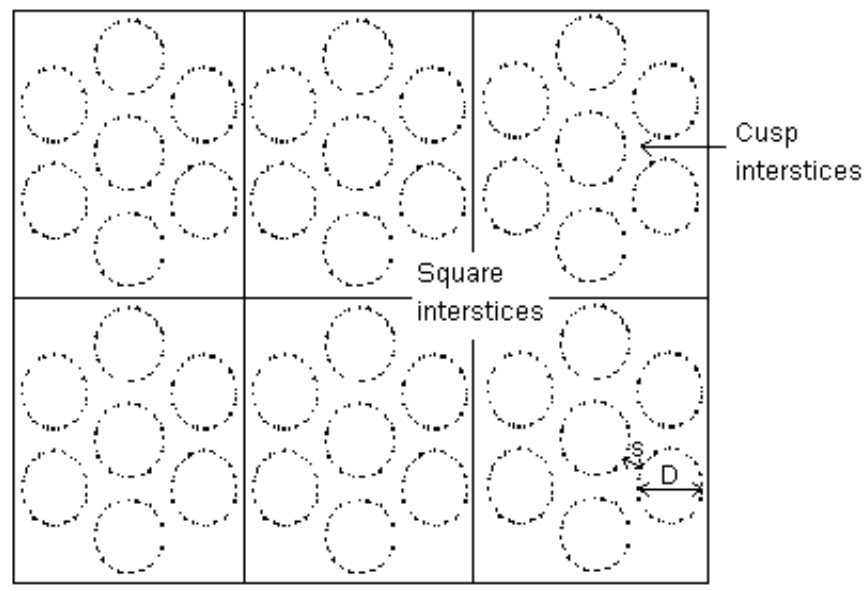

Fig. 1. Schematic diagram of bundles of SWNTs [19].

We use a hydroxyl group to represent the functional group as done in Müller et al. [32]. It is modeled as a $\mathrm{LJ}$ dispersive site at the centre of oxygen atom and a single square well (SW) site at the hydrogen atom, and their molecular parameters are the same as those of the water potential model except the hydrogen bond strength. The potential well depth between the hydrogen atom on a hydroxyl group and the lone pair of electrons on a water molecule to form hydrogen bond is $5000 \mathrm{~K}$ [32]. In this paper, we use 1 and $3 \mathrm{OH}$ groups positioned either (1) at the middle, (2) at the edge of the central tube of a bundle or (3) at the middle of an outer tube near the square interstice, as shown in Fig. 2. For the slit pore model, the hydroxyl group is located either at the edge or at the center of innermost layer of the upper wall. We used either two or six functional groups. The distance of the LJ site of the $\mathrm{OH}$ group from the pore wall is $1.364 \AA$ and the SW site is placed at $1.2852 \AA$ from the LJ centre with an angle of 109 [32].

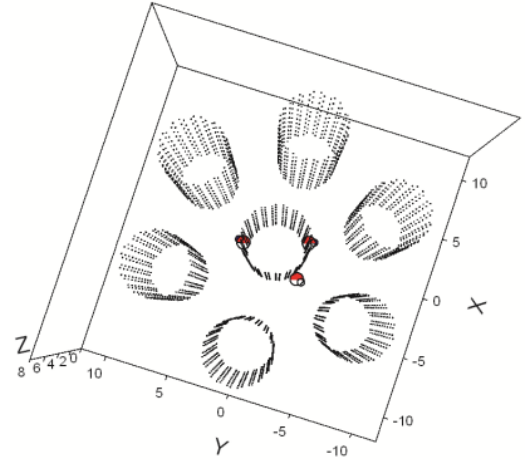

2a) Middle topology for $3 \mathrm{OH}$ groups

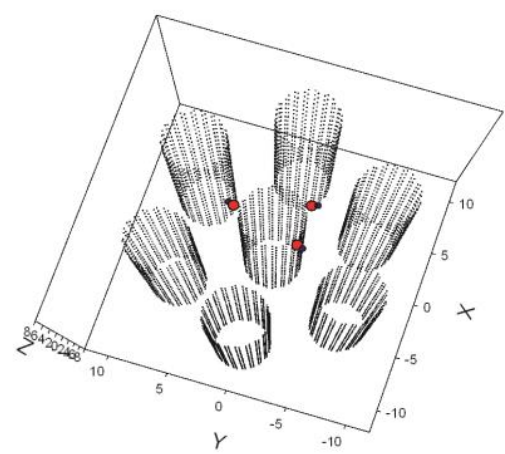

2b) Edge topology for $3 \mathrm{OH}$ groups

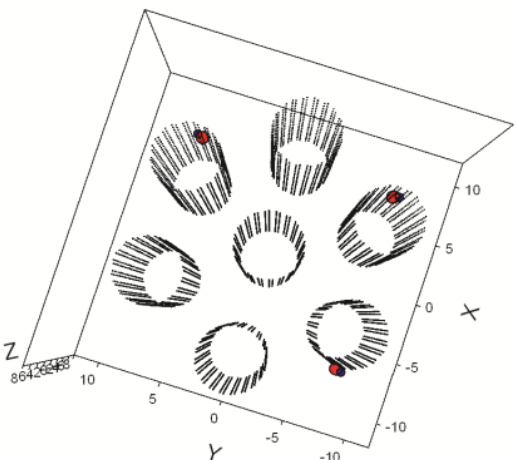

2c) square interstices topology for $3 \mathrm{OH}$ groups

Fig. 2 The solid configuration for a) middle, b) edge and c) square interstices topologies for the bundle of tubes. Big red spheres represent oxygen atoms while small black spheres represent hydrogen atoms of the OH groups. 


\subsection{Simulation Method}

The simulation box used for carbon nanotubes bundle is a rectangular box with the $z$-dimension the same as the tube length while the $x$ - and $y$-dimensions depend on the tube diameter and the spacing to accommodate seven tubes. A tube length of $50 \AA$ is chosen in this study. The simulation box is shown in Fig. 3 and the length in $x$ and $y$ directions can be calculated from the following equations.

$$
L_{x}=3(D+s) ; \quad L_{y}=2\left\{\left(\frac{3 D}{2}+s\right) \sin \left(\frac{\pi}{3}\right)\right\}+s
$$

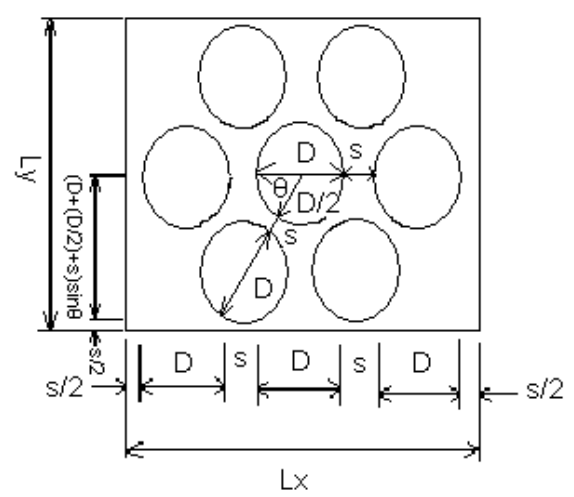

Fig. 3 A bundle of seven tubes of diameter $\mathrm{D}$ located at the middle of the simulation box and a separation spacing of $s$.

For the slit model, the $x$-and $y$-dimensions are 37.6 and $39.4 \AA$, respectively, the box height is the same as the pore width. Grand Canonical Monte Carlo method (GCMC) with the Metropolis algorithm is used to obtain adsorption isotherms. For adsorption, we started with an empty box, and the simulation is carried out at a given chemical potential until the system has reached equilibrium. Once this is achieved, the chemical potential is increased, and the final configuration of molecules of the previous chemical potential is used as the initial configuration for the new simulation. For each point on the adsorption branch, 700 million configurations are used to reach equilibrium and to obtain ensemble averages. For desorption, the simulation process is reversed, by starting with the highest chemical potential, until the simulation box is empty.

The maximum displacement step length is initially chosen as half of the collision diameter of water, and during the equilibration stage it is decreased by $5 \%$ when the acceptance ratio is less than 0.5 and increased by $5 \%$ when it is greater than 0.5 . The virial equation [32] is used to determine the relative pressure of the bulk gaseous phase for a given chemical potential. In the case of finite-length pore, the particle move is rejected if the particle is displaced to a position outside the simulation box. To study the effects of functional group and temperature on water adsorption, simulations are carried out at 278, 293, 298 and 303 K.

\subsection{Experiment}

\subsubsection{Preparation and Characterization of Activated Carbon}

In this study, dried Eucalyptus wood chips are used as the precursor for AC. The preparation of activated carbon using physical activation (ACP) was as follows; the chip was milled by a rotor beater mill and sieved to obtain a size fraction of $20 \times 30$ mesh (average size $0.714 \mathrm{~mm}$.) and then carbonized in a horizontal ceramic tube furnace at $673 \mathrm{~K}$ for 1 hour under a nitrogen flow of $100 \mathrm{ml} / \mathrm{min}$. The resulting char was then activated under constant flow of $200 \mathrm{ml} / \mathrm{min}$ of (50:50) nitrogen and carbon dioxide mixture at $873 \mathrm{~K}$ for 1 hour, followed by cooling down to room temperature under nitrogen atmosphere. The same procedure is applied for activated carbon prepared using chemical activation (ACC), however the sieved wood chip was impregnated in phosphoric acid $50 \%$ by wt. for 1 hour and then carbonized. To increase the functional 
group concentration, ACC was treated with hydrogen peroxide 35\% wt. at $298 \mathrm{~K}$ for 24 hours while ACP was treated with nitric acid $1 \mathrm{M}$ at $363 \mathrm{~K}$ for 24 hours.

The carbon samples were characterized for the structural porous properties (BET-area and total pore volume) by $\mathrm{N}_{2}$ adsorption at $77 \mathrm{~K}$ by using an automated adsorption apparatus (ASAP2010 Micromeritics, USA). The pore size distribution was determined with the density functional theory (DFT). This method also gave the micropore volume which was calculated from the cumulative volume of the pores smaller than $20 \AA$. Procedures for the analysis of oxygen functional group are taken from Boehm [33].

\subsubsection{Water Adsorption Measurement}

Water vapor adsorption was carried out with an Intelligent Gravimetric Analyzer (IGA) supplied by Hiden Analytical Ltd as shown in Fig. 4. Prior to each measurement, the adsorbent (typical about $200 \mathrm{mg}$ ) is outgassed until a constant weight is achieved at a pressure of $10^{-6} \mathrm{mbar}$ and $473 \mathrm{~K}$. HPLC grade water supplied by RCI-LabScan is used as adsorbate, and dissolved gases are removed by repeated evacuation and vapor equilibration cycles. The weight change as a function of time is analyzed in real-time with a computer algorithm to ensure that the system has reached equilibrium.

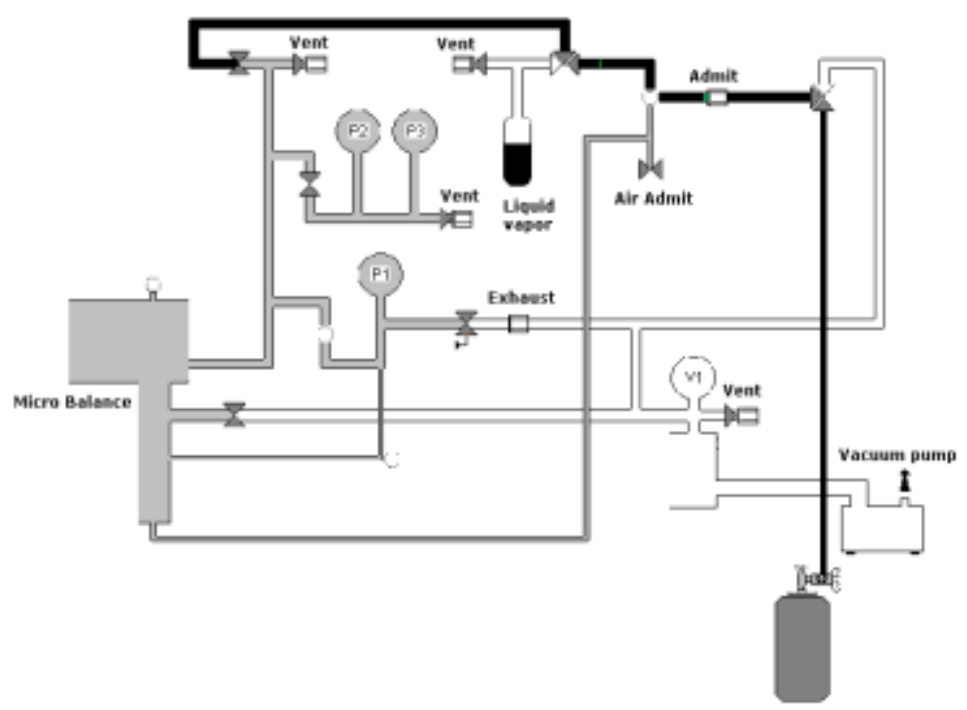

Fig. 4 An Intelligent Gravimetric Analyzer (IGA) for water adsorption measurement.

\section{Results and Discussions}

\subsection{Effects of Functional Group on the Adsorption of Water}

\subsubsection{Adsorption of Water in Homogeneous and Heterogeneous Slit Pore Models}

The effects of functional group on water adsorption in 10 and $16 \AA$ slits are presented in Figs. 5 and 6 for the Müller et al.'s and SPCE models, respectively, with the centre configuration of OH. For comparison, we also showed the isotherms for homogeneous pores (no functional group), where we see that the adsorption branch shows a steep increase at a pressure greater than $\mathrm{P}_{0}$; a feature of weak interaction between water and graphene surface, that is well known in the literature [23]. 

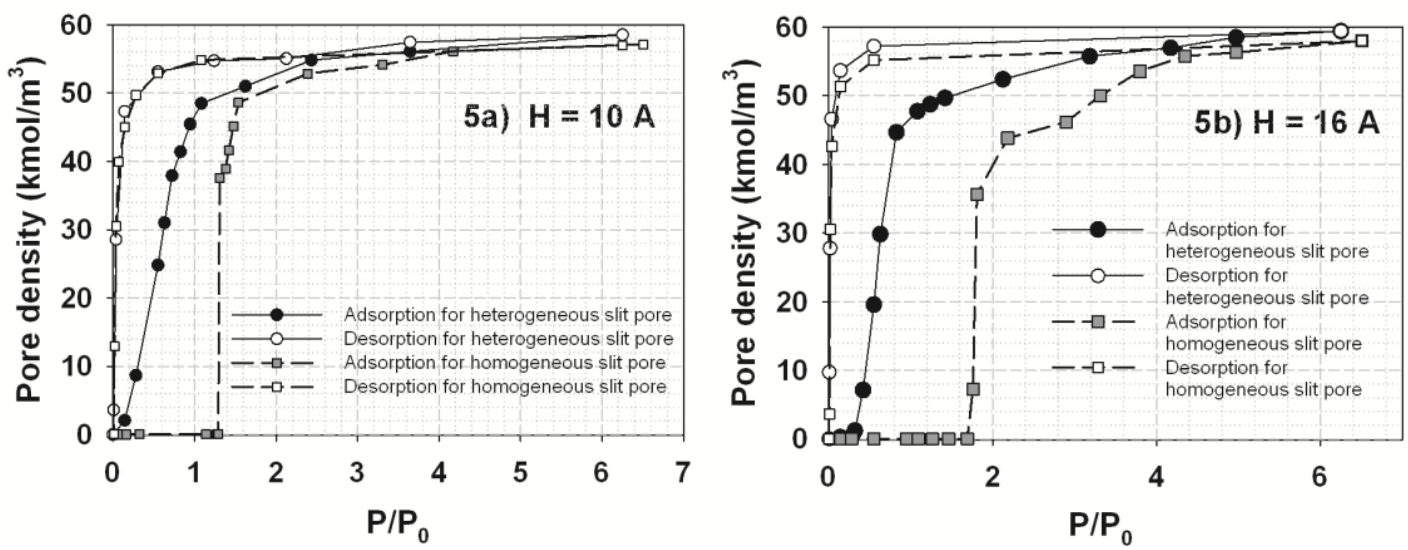

Fig. 5 Adsorption isotherms at $298 \mathrm{~K}$ for the Müller et al. water model in slits whose widths are $10 \AA$ (a) and $16 \AA(b)$.
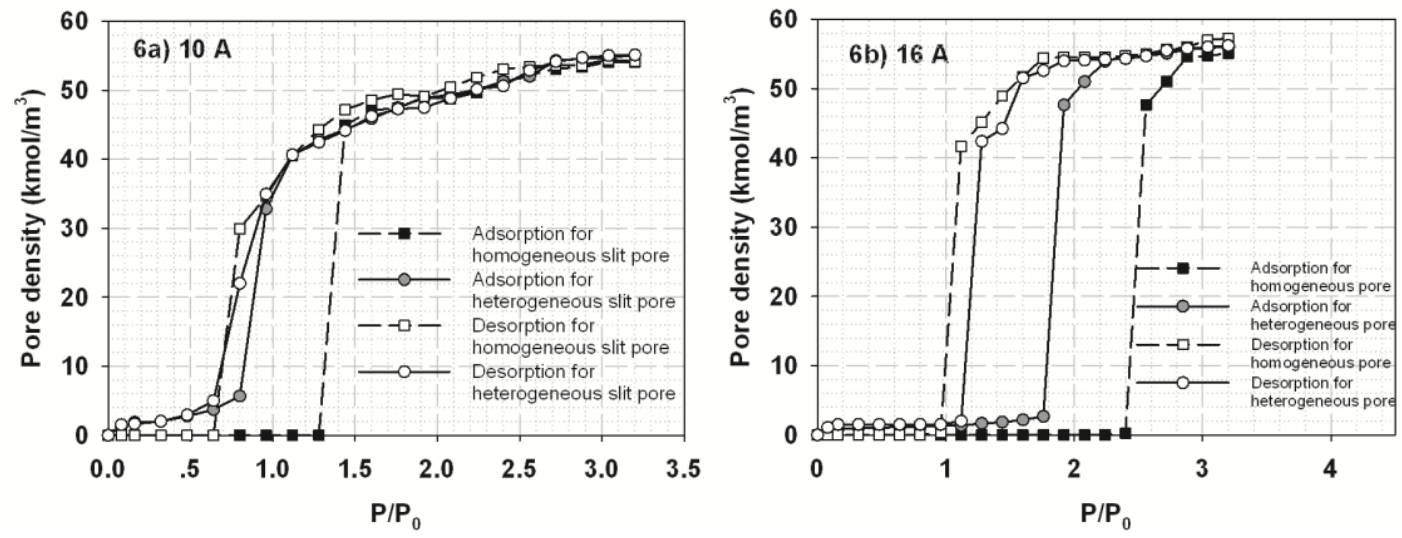

Fig. 6 Adsorption isotherms at $298 \mathrm{~K}$ for SPCE water model in slits whose widths are $10 \AA$ (a) and $16 \AA$ (b).

Observing the isotherms in the presence of functional groups, we note the following features:

(i) an early onset of adsorption isotherm, due to the clustering of water molecules around the functional groups, resulting from the strong interaction between water and functional group, and

(ii) the hysteresis loop is smaller, and this is due to the early onset of adsorption and the desorption branch is not affected by the presence of the functional group because desorption is governed by the fluid-fluid interaction.

\subsubsection{Adsorption of Water in Homogeneous and Heterogeneous Bundle of Tubes}

The isotherm of water adsorption at $298 \mathrm{~K}$ for bundles of tubes whose diameters are 10.8 and $13.6 \AA$ and the spacing between tubes is $4 \AA$ with $1 \mathrm{OH}$ group placed at the middle of the exterior surface of the central tube (middle topology) are shown in Figs. 7(a) and 7(b), respectively. For comparison, we also present the isotherms for homogeneous tube bundle. The adsorptive capacity has two contributions: one from inside the tubes and the other from the interstices between the tubes.

Adsorption is dominated by that inside the tubes (intra-tube adsorption), despite of the stronger solidfluid interactions in the interstices and the strong fluid-functional group interactions. This is because of the geometrical constraint of the interstices that prevent clustering of water [19]. The pore filling pressure of the intra-tube adsorption increases in the larger tube, due to its lower solid-fluid potential. 

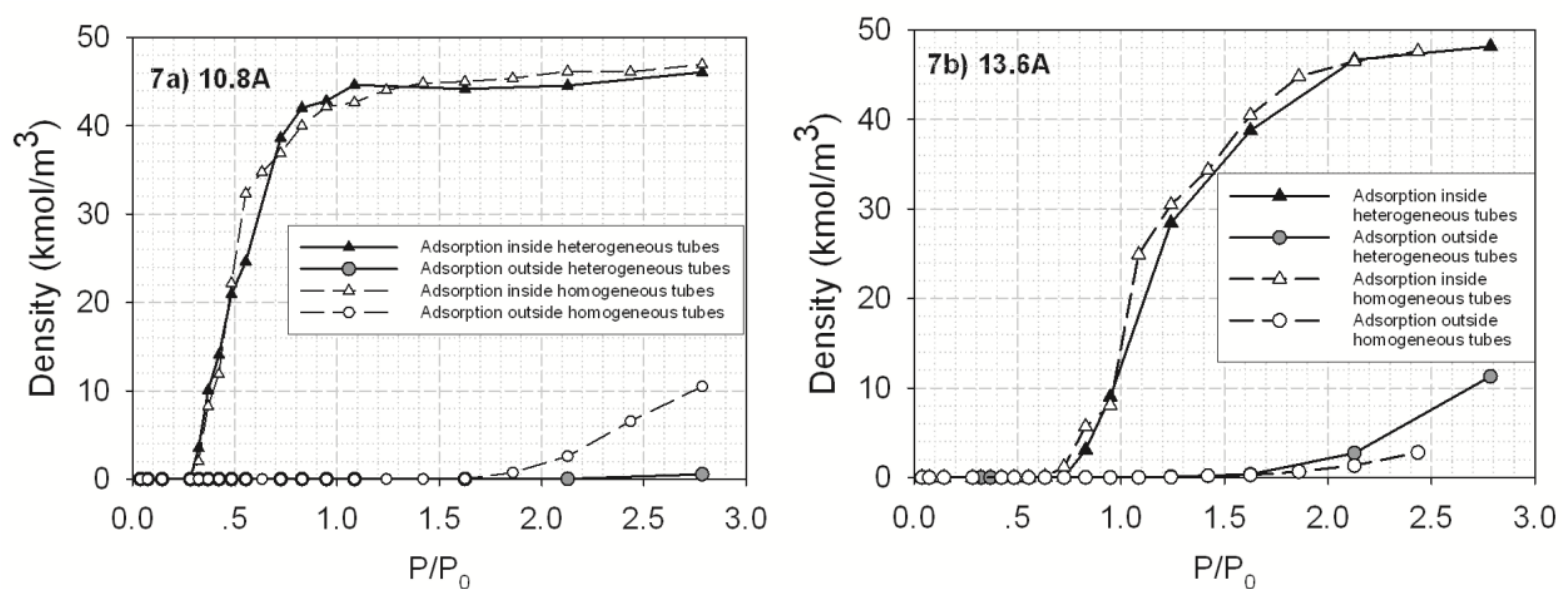

Fig. 7 The adsorption isotherms of the Müller et al. water in homogeneous (unfilled symbols) and heterogeneous $(\mathrm{OH}$ at the middle of the exterior surface of the central tube, filled symbols) at $298 \mathrm{~K}$ for tube bundles of tubes having diameter of $10.8 \AA$ (a) and $13.6 \AA$ (b).

Figure 8 shows the isosteric heats in bundles of 10.8 and $13.6 \AA$ tubes, in the absence and presence of functional group. At very low loading, the isosteric heat is lower than the condensation heat, $\mathrm{H}_{\text {liq, }}$ when the density increase, the heat increases above the condensation heat, which is due to the combined effects clustering of water molecules and the interaction of water with graphene surfaces.

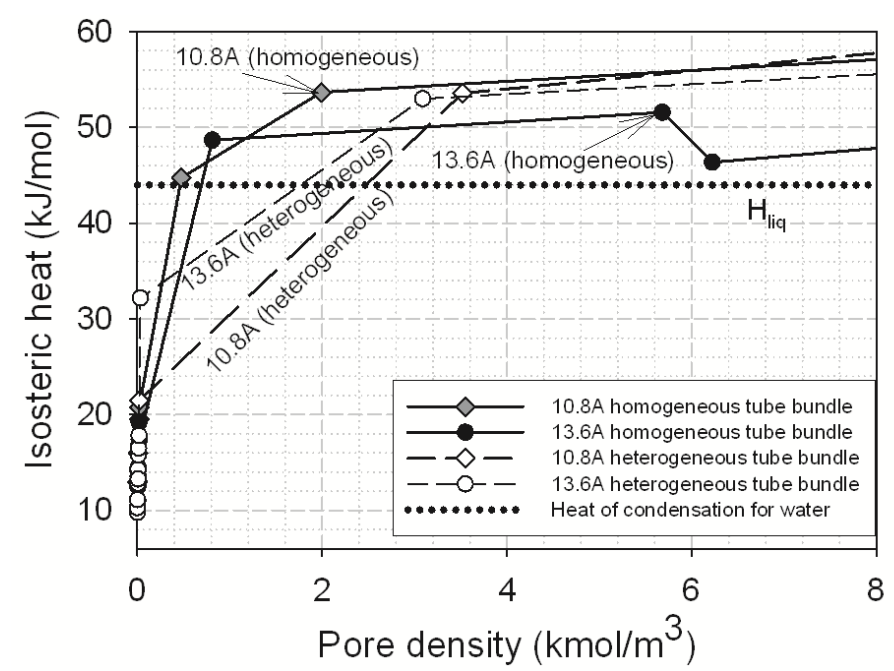

Fig. 8 The isosteric heats for the Müller et al. water adsorption in homogeneous (solid line) and heterogeneous (dashed line) carbon nanotubes with different diameter at $298 \mathrm{~K}$. The horizontal dashed line is the heat of condensation of bulk water $(44 \mathrm{~kJ} / \mathrm{mol})$.

\subsection{Effects of Functional Group's Location and Amount of Functional Group on The Adsorption Isotherm}

\subsubsection{Slit Pore Model}

Two configurations of functional groups were considered: edge and centre, and the separation distance, $\delta$, between two adjacent functional group is $4.26 \AA$. This spacing was derived in our earlier study [22] where we investigated different spacing and found that $4.26 \AA$ is the most suitable to describe water adsorption. Figure 9 shows the isotherms obtained for heterogeneous finite pores with these two configurations of functional group. 

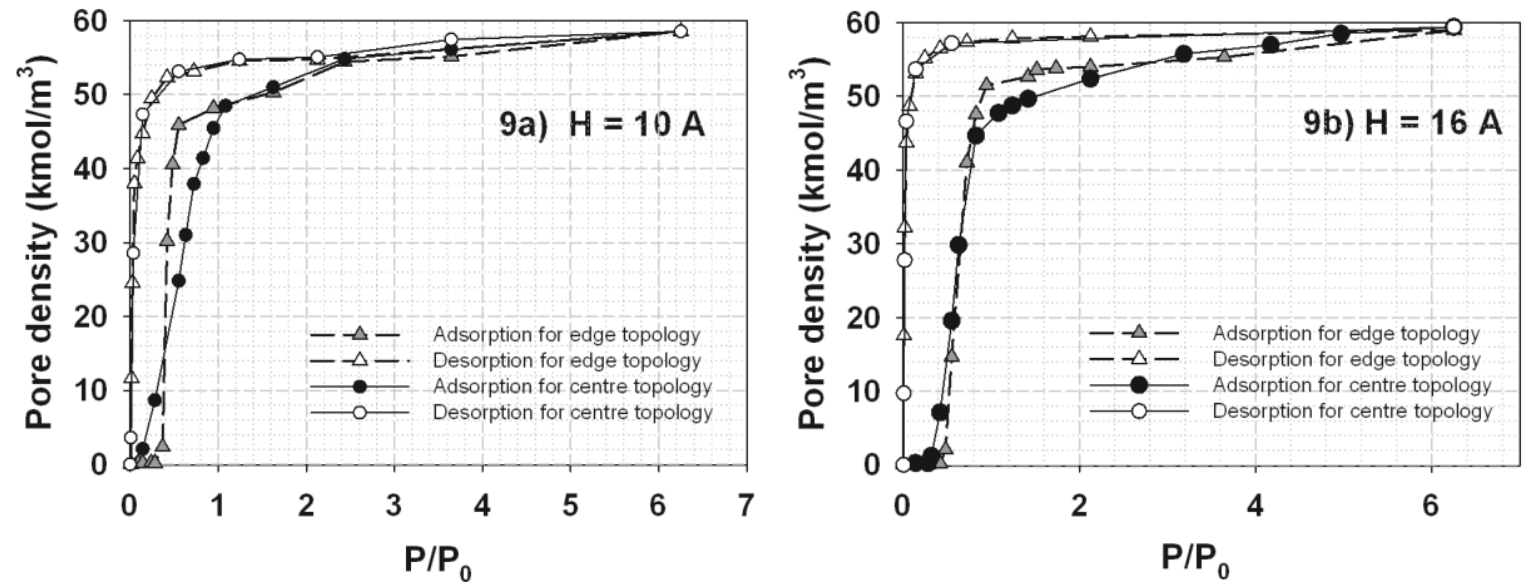

Fig. 9 Adsorption isotherms at $298 \mathrm{~K}$ for the Müller et al. water model in slits whose widths are $10 \AA$ (a) and $16 \AA$ (b) (triangle symbols for pore with edge topology while circles for pore with centre topology; filled symbols for adsorption and unfilled symbols for desorption)

At low loadings, adsorption is enhanced with the central configuration because water clusters on a functional group are stabilized by carbon atoms around it. In the edge configuration, this stabilization effect is absent. This is consistent with what was observed in the literature [21, 24-25].

Figure 10 shows the snapshots of water molecules in heterogeneous pores of $10 \AA$ and $16 \AA$. For clarity, we show only one graphene layer of each wall. We observe that water molecules nucleate around the functional group. Once nucleated, the water cluster grows in all directions but predominantly in the direction perpendicular to the pore wall. This is due to the tetrahedral structure of the Müller et al. model, in which one lone pair of electrons of water molecule forms hydrogen bond with the functional group. This makes two hydrogen atoms and the remaining lone pair of electrons of that water molecule pointing downward, and they are available for the other water molecules to form hydrogen bond with [22].
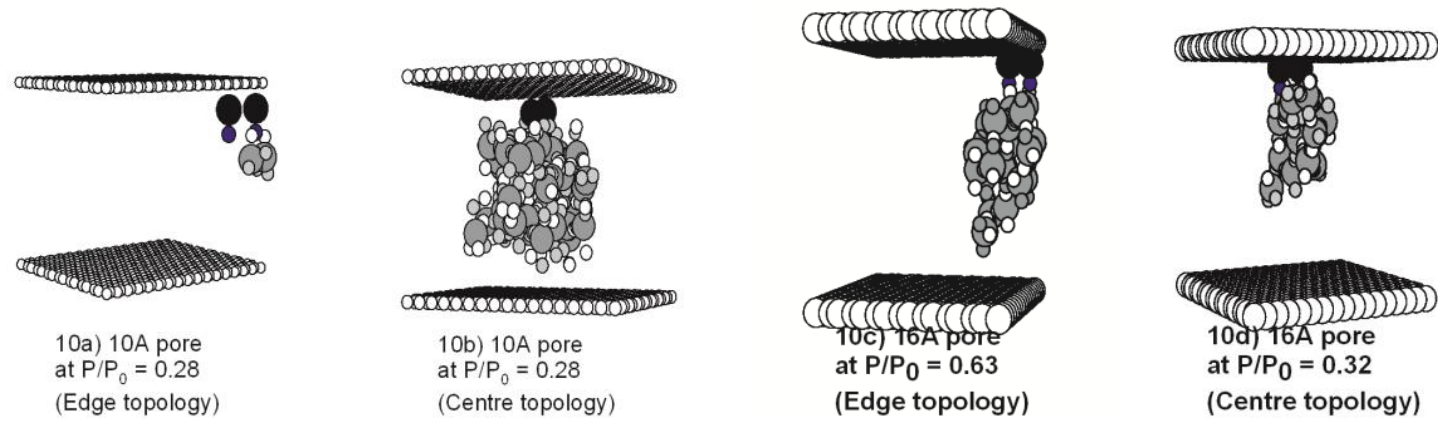

Fig. 10 Snapshots of the Müller et al. water molecules in heterogeneous finite-length slit pores for width of 10 and 16 Á. In these figures, big white spheres represent carbon atoms, big and small black spheres represent oxygen and hydrogen atoms of hydroxyl group, respectively, and big dark gray spheres represent oxygen atoms of water while small gray spheres and small white spheres represent hydrogen atoms and lone pair electrons of water molecules, respectively.

\subsubsection{Carbon Nanotubes Bundle}

Figure 11 shows the effects of the location of functional group on adsorption in bundles of 10.8 and $13.6 \AA$ tubes, with $4 \AA$ spacing. Two locations of the functional group are associated with the central tube: (i) at the middle of the exterior surface, (ii) at the edge, and one location at the middle of an outer tube near the square interstice. The isotherms of the corresponding bundles of homogeneous tube are also plotted in the same figure as dashed lines. 

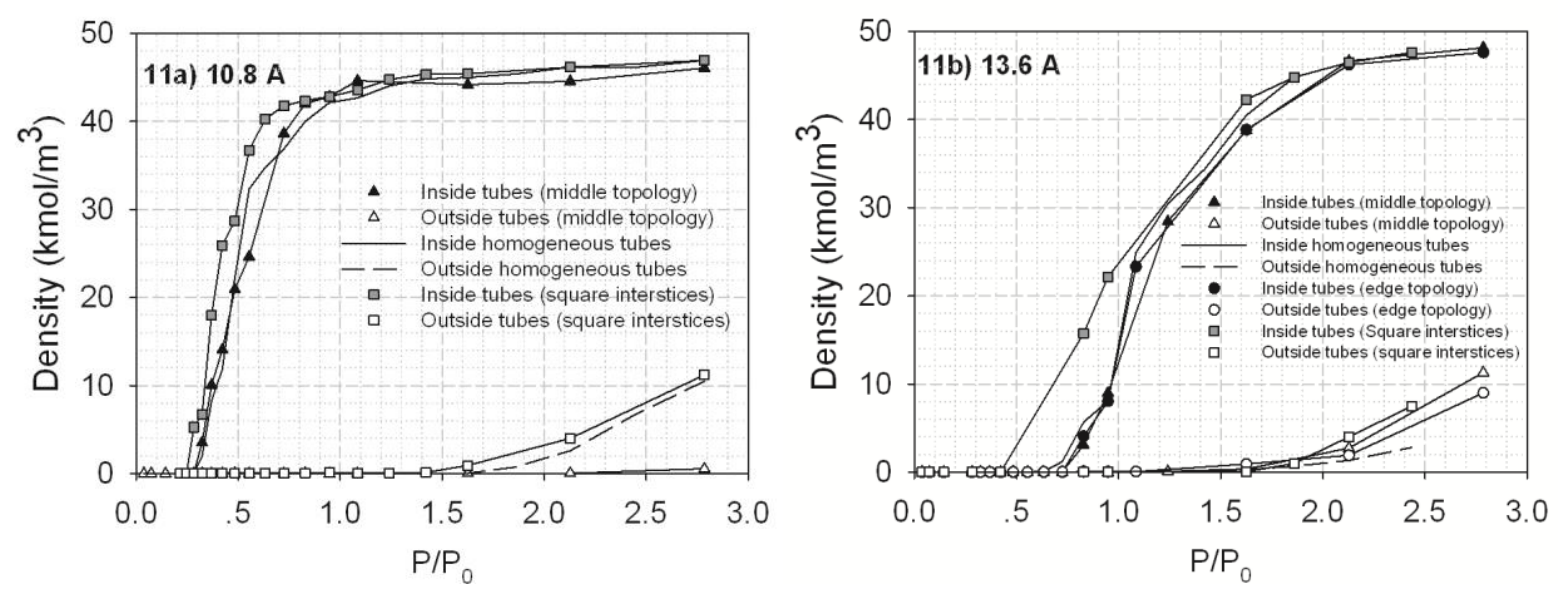

Fig. 11 The adsorption isotherms of the Müller et al. water in heterogeneous tubes at $298 \mathrm{~K}$ for different topology of functional group for $10.8 \AA$. (a) and $13.6 \AA$ (b).

It is seen that water adsorbs mostly inside the tubes because the inter-tube spacing is too small for the formation of water cluster. The simulation results show a similar behavior to the experimental data observed by Maniwa et al. [34] for water adsorption in bundle of $13.5 \AA$ tubes. An early onset of isotherm for the square interstice topology is observed, and this is due to the contribution of the greater waterfunctional group interaction at the square interstice which is large enough for water molecules to form hydrogen bonds around the functional group and to grow into large aggregates. This is supported with the snapshots of water molecules in the bundle of $10.8 \AA$ tubes at various pressures as shown in Fig. 12.

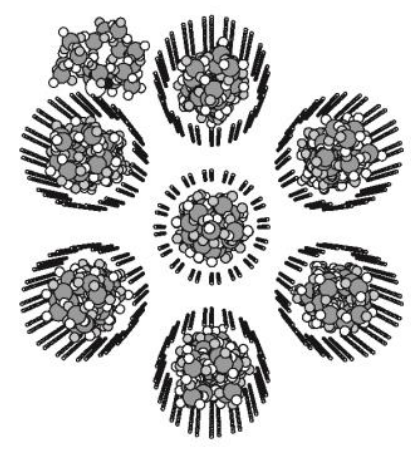

12a) $P / P_{0}=1.62$

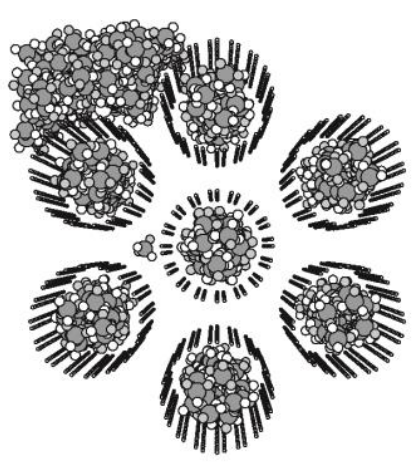

12b) $P / P_{0}=2.1$

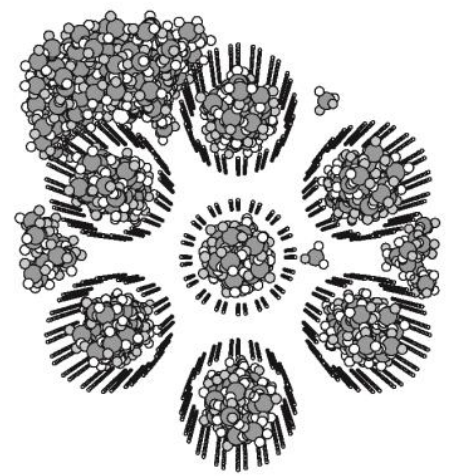

12c) $P / P_{0}=2.8$

Fig. 12 Snapshots of water molecules in bundle of $10.8 \AA$ tubes at various pressures for square interstice topology. In these figures, big white sphere and small black sphere represent oxygen and hydrogen atoms of hydroxyl group, respectively, and big dark gray spheres represent oxygen atoms of water while small gray spheres and small white spheres represent hydrogen atoms and lone pair electrons of water molecules, respectively.

\subsubsection{Effects of Amount of Functional Group}

For slit pore, we grafted two and six functional groups on the innermost layer of the upper wall with the separation distance $(\delta)$ of $4.26 \AA$, two configurations of functional groups, edge and centre topologies were investigated. The pore density increases with an increase of functional group as physically expected. This behavior agrees with the experimental data observed by Morimoto and Miura [35] which shown that the increase amount of functional groups leads to a drastically increase of the amount of adsorbed water.

In the case of SWNT with a spacing of $4 \AA$, one and three $\mathrm{OH}$ groups were grafted at the edge of the exterior surface of the central tube, and the spacing between functional groups is $11.3 \AA$. It is found that the adsorption for heterogeneous tubes with $3 \mathrm{OH}$ groups is greater than that with $1 \mathrm{OH}$ group; this is due 
to the greater functional group-water interaction. Even though the adsorption outside the tube increases with the amount of functional group, the dominance of adsorption is due to the intra-tube adsorption.

\subsection{Effects of Separation Spacing Between Tubes}

Figure 13 shows the effects of the separation spacing on adsorption in bundles of 10.8, and 13.6 $\AA$ SWNTs with the middle topology of one OH group. Two separation spacings, $4 \AA$ and $10 \AA$ were considered. For $10.8 \AA$ tubes, the adsorption inside the tube is unaffected by the spacing. But for bundles of $13.6 \AA$ tubes, the onset of adsorption shifts to lower pressure for larger spacing. This is due to the contribution of the greater fluid-fluid and electrostatic interactions [19] that results in the favourable formation of clusters.
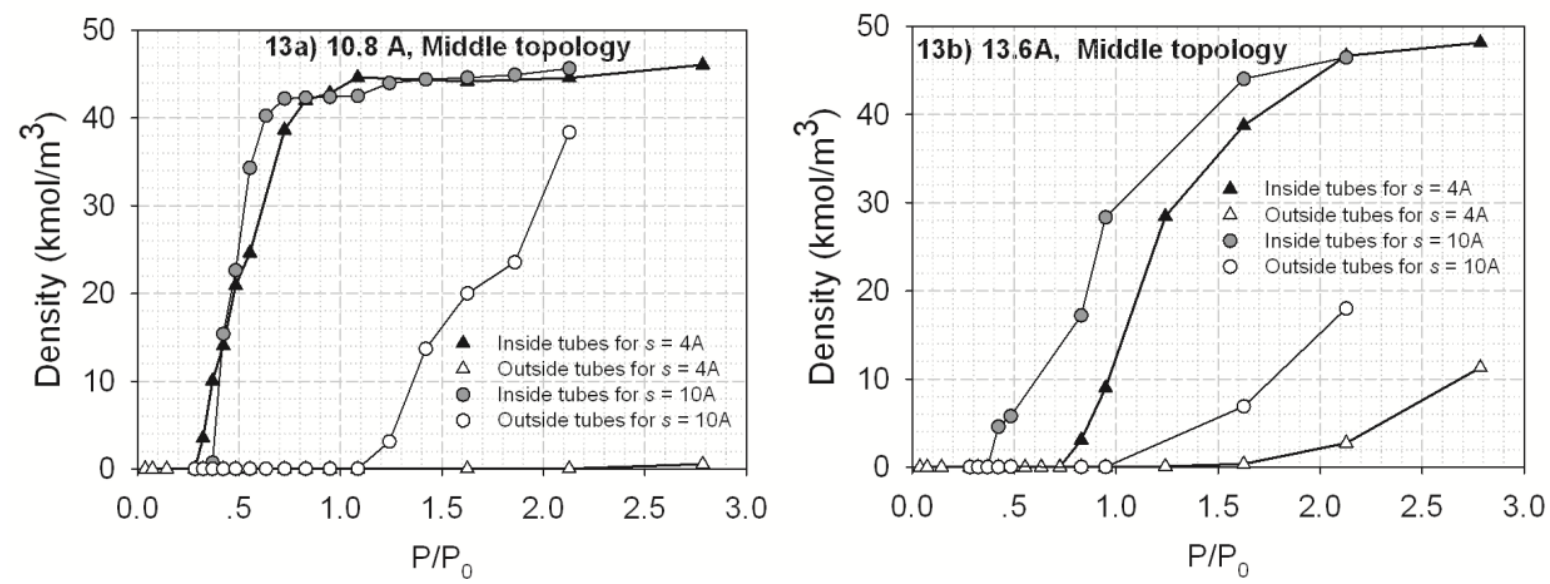

Fig. 13 The adsorption isotherms of water in heterogeneous bundle of 10.8 and $13.6 \AA$ tubes with one $\mathrm{OH}$ group placed at the middle of exterior surface of the central tube at various separation spacing.

\subsection{Comparison between the Simulation Results and the Experimental Data}

\subsubsection{Adsorption of Water in Activated Carbon}

The structural properties of ACPs and ACCs for modified and unmodified surfaces determined from nitrogen adsorption isotherms at $77 \mathrm{~K}$ and the surface functional groups are shown in Table 3 . The experimental data of water adsorption at $298 \mathrm{~K}$ are shown in Fig. 14.

Table 3 Porous properties of activated carbons used in this study.

\begin{tabular}{|c|c|c|c|c|c|c|c|}
\hline Sample & $\begin{array}{c}\text { BET } \\
\text { area } \\
\left(\mathrm{m}^{2} / \mathrm{g}\right)\end{array}$ & $\begin{array}{l}\text { Micropore } \\
\text { volume } \\
\text { (cc/g) }\end{array}$ & $\begin{array}{c}\text { Meso- and } \\
\text { macropores } \\
\text { volume } \\
(\mathrm{cc} / \mathrm{g})\end{array}$ & $\begin{array}{c}\text { Total } \\
\text { pore } \\
\text { volume } \\
(\mathrm{cc} / \mathrm{g}) \\
\end{array}$ & $\begin{array}{c}\text { Acidic } \\
\text { group } \\
(\mathrm{mmol} / \mathrm{g})\end{array}$ & $\begin{array}{c}\text { Basic } \\
\text { group } \\
(\mathrm{mmol} / \mathrm{g})\end{array}$ & $\begin{array}{r}\text { Total } \\
\text { functional } \\
\text { group } \\
(\mathrm{mmol} / \mathrm{g}) \\
\end{array}$ \\
\hline ACC & 1200 & 0.55 & 0.03 & 0.58 & 0.66 & 0.63 & 1.29 \\
\hline $\begin{array}{l}\text { ACC- } \\
\mathrm{H}_{2} \mathrm{O}_{2}\end{array}$ & 689 & 0.34 & 0.01 & 0.35 & 1.67 & 0.40 & 2.07 \\
\hline ACP & 460 & 0.21 & 0.02 & 0.23 & 1.20 & 0.40 & 1.60 \\
\hline $\begin{array}{l}\text { ACP- } \\
\mathrm{HNO}_{3}\end{array}$ & 405 & 0.20 & 0.03 & 0.23 & 1.98 & 0.60 & 2.58 \\
\hline
\end{tabular}




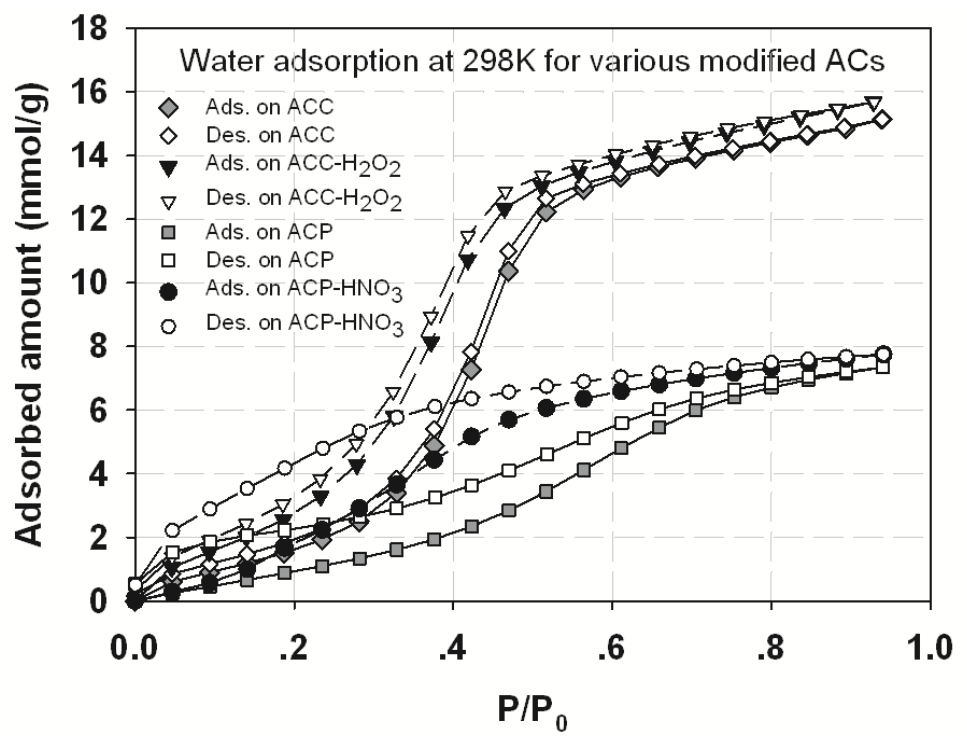

Fig. 14 The experimental isotherms of water in various activated carbons at $298 \mathrm{~K}$.

The experimental isotherms of ACCs show a modest increase for relative pressures less than 0.3 , after which the isotherm increases sharply, which is the typical behavior of water adsorption in micropores. The onset of filling occurs at lower pressure than what typically observed in the literature [25], and this is due to the high concentration of functional groups in our activated carbons. The behavior of ACP is the same as that of ACC, but the S-shape pattern of ACP is less pronounced because of its lower micropore volume. For ACC- $\mathrm{H}_{2} \mathrm{O}_{2}$, the micropore volume is reduced by half from its parent ACC, but the total functional group concentration is doubled. However the $\mathrm{ACP}-\mathrm{HNO}_{3}$ is oxidized with nitric acid (which is milder than $\mathrm{H}_{2} \mathrm{O}_{2}$ ), the micropore volume is barely affected and the concentration of the functional group is increased by $50 \%$ as shown in Table 3 . The reduction in surface area and pore volume of oxidized carbons, especially ACC- $\mathrm{H}_{2} \mathrm{O}_{2}$, is due to an inaccessibility of the probe molecules into the pore interior caused by the oxidation reaction between oxidizing agent and unstable covalent bond between carbons, leading to the partial collapse of pore walls [36].

To describe the experimental isotherms, we use a set of local isotherms of 10,16 and $20 \AA$ pores having edge and centre topologies, and choose two and six hydroxyl groups to characterize unmodified and modified activated carbons, respectively. As a result of the fitting of the theoretical results and the experimental data (shown in Fig. 15), the pore volume distributions were derived and tabulated in Table 4. For comparison, the total pore volume obtained from the nitrogen adsorption is presented in the same table.

Table 4 Pore size distribution for various kinds of activated carbons used in this study.

\begin{tabular}{|c|c|c|c|c|c|c|}
\hline Sample & $\begin{array}{l}\text { Volume of } \\
10 \AA \text { pore } \\
\text { with corner } \\
\text { topology } \\
\text { (cc/g) }\end{array}$ & $\begin{array}{l}\text { Volume of } \\
10 \AA \text { pore } \\
\text { with centre } \\
\text { topology } \\
\text { (cc/g) }\end{array}$ & $\begin{array}{l}\text { Volume of } \\
16 \AA \text { pore } \\
\text { with centre } \\
\text { topology } \\
\text { (cc/g) }\end{array}$ & $\begin{array}{l}\text { Volume } \\
\text { of } 20 \AA \\
\text { pore with } \\
\text { centre } \\
\text { topology } \\
\text { (cc/g) }\end{array}$ & $\begin{array}{l}\text { Total pore } \\
\text { volume from } \\
\text { adsorption } \\
\text { of water and } \\
\text { finite-length } \\
\text { pore }(\mathrm{cc} / \mathrm{g})\end{array}$ & $\begin{array}{r}\text { Total pore } \\
\text { volume from } \\
\text { nitrogen } \\
\text { adsorption } \\
\text { at } 77 \mathrm{~K} \\
(\mathrm{cc} / \mathrm{g})\end{array}$ \\
\hline ACC & 0.11 & 0.25 & 0.05 & 0.05 & 0.46 & 0.58 \\
\hline ACC- $\mathrm{H}_{2} \mathrm{O}_{2}$ & 0.14 & 0.29 & 0.04 & 0.03 & 0.50 & 0.35 \\
\hline $\mathrm{ACP}$ & 0.01 & 0.10 & 0.04 & 0.03 & 0.18 & 0.23 \\
\hline $\mathrm{ACP}-\mathrm{HNO}_{3}$ & 0.08 & 0.12 & 0.04 & 0.02 & 0.26 & 0.23 \\
\hline
\end{tabular}



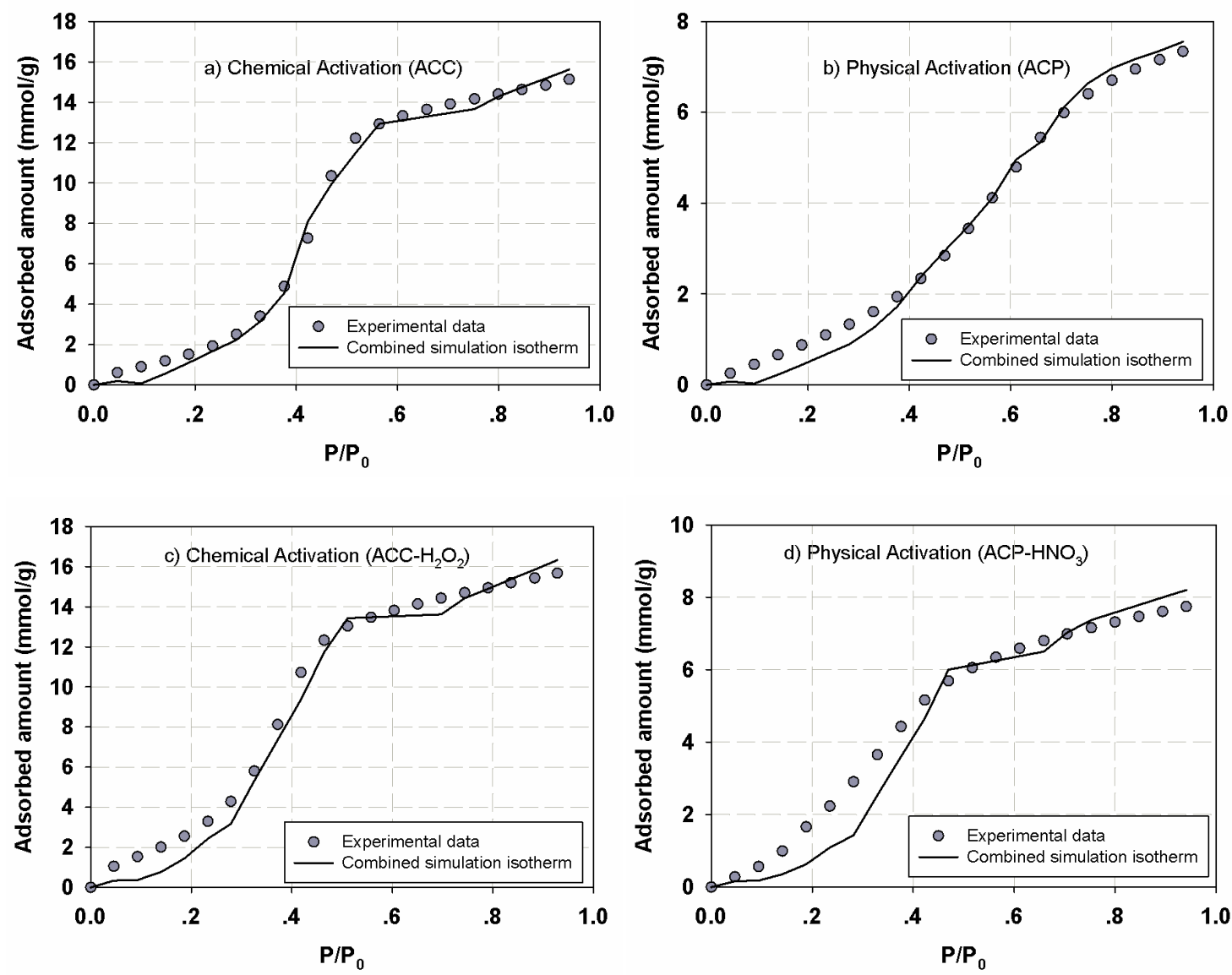

Fig. 15 The experimental isotherm of water in various activated carbons at $298 \mathrm{~K}$ (circle symbols) and the combined simulation isotherm (solid line) at the same temperature.

The agreement between the theory and the experimental data is regarded as satisfactory. Better agreement might be possible with more pore sizes considered and variable functional groups distributed along the pore walls. For unmodified carbons (ACC and ACP) the total pore volumes determined by water adsorption are less than those by nitrogen adsorption, and this is due to the amount of functional group is not high enough and clusters formed are not of sufficient sizes to enter small mesopores; on the other hand, for the modified carbons, total volumes determined by water adsorption are greater, and this is probably due to the contribution of water clusters outside the pores.

\subsubsection{Adsorption of Water in Carbon Nanotubes}

SWNTs were supplied by Cheap Tube Inc., and the diameters were in the range between 1 to $2 \mathrm{~nm}$ (Fig. 16). The experimental data for the modified nanotubes is greater than the unmodified one which is due to the favorable adsorption of water molecules around functional groups. For unmodified sample, we used the simulation results of 10.8 and $13.6 \AA$ tubes without functional group to fit the experimental data. The good agreement between the combined isotherm and data is shown in Fig. 17. It is found that the specific pore volumes of 10.8 and $13.6 \AA$ tubes are 0.009 and $0.21 \mathrm{cc} / \mathrm{g}$, respectively, giving a total pore volume of 0.219 $\mathrm{cc} / \mathrm{g}$ which is less than that determined by nitrogen adsorption of $0.43 \mathrm{cc} / \mathrm{g}$. The reason for this difference is similar to what was discussed above for activated carbon. 


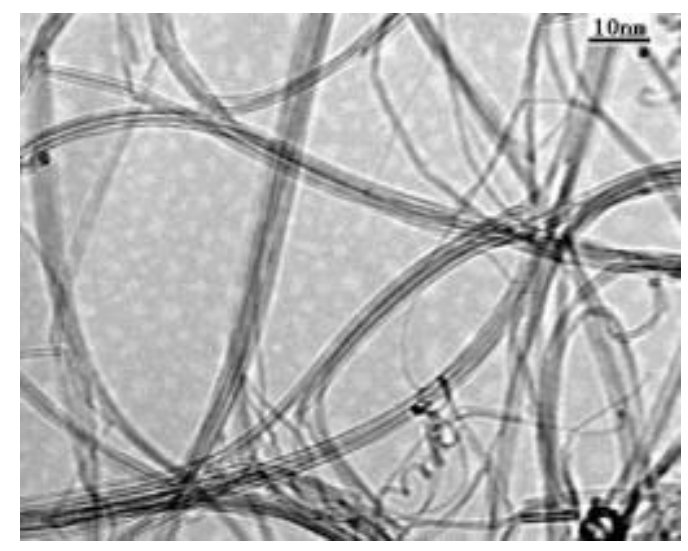

Fig. 16 The FESEM image of unmodified CNT, provided by Cheap Tube Inc. [37].

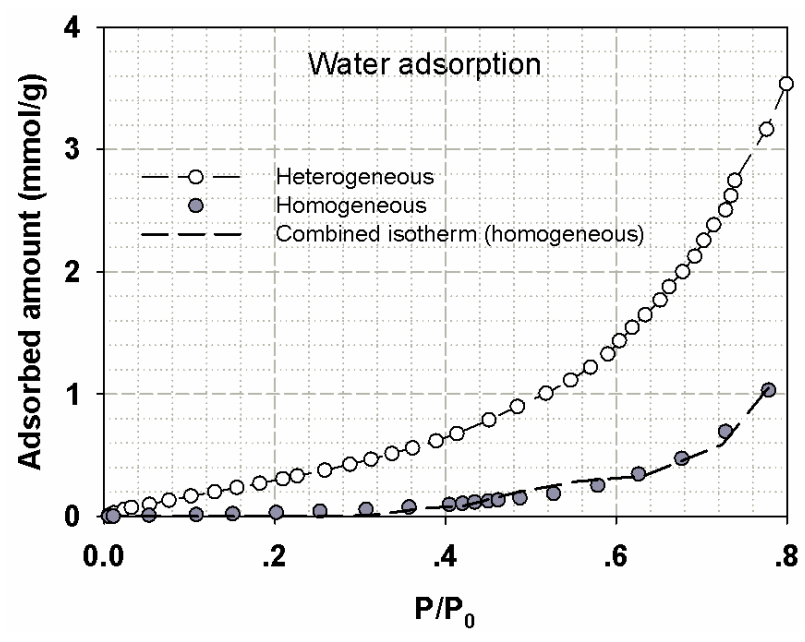

Fig. 17 The experimental data of water adsorption in modified and unmodified carbon nanotubes at $293 \mathrm{~K}$ and the combined isotherm of water in homogeneous pores of 10.8 and $13.6 \AA$ at $298 \mathrm{~K}$.

\subsection{Adsorption of Water in Activated Carbon at Different Temperatures.}

Figure 18 shows the experimental water isotherms for ACC versus relative pressure at a range of temperatures from 10 to $30^{\circ} \mathrm{C}$. Typically adsorption increases with a decrease in temperature, because adsorption is an exothermic process. However, we observe an unusual behavior at $10{ }^{\circ} \mathrm{C}$, at which the isotherm is, in fact, less than that at $15^{\circ} \mathrm{C}$. To seek an explanation for this, we carried out simulation of the adsorption of SPCE water in 8 and $30 \AA$ pores at 5,20 and $30^{\circ} \mathrm{C}$ and presented the results in Fig. 19.

Interestingly, we reproduce this unusual behavior of water adsorption at low temperatures: the simulated isotherm at $5{ }^{\circ} \mathrm{C}$ is less than that at $20^{\circ} \mathrm{C}$. At $20^{\circ} \mathrm{C}$, water molecules are nucleated around the functional groups, once water clusters outside the pore are large enough, water molecules enter the pore, following the pore-filling mechanism. The water clusters can grow in all directions but predominantly in the direction perpendicular to the pore wall [25]. However, at $5{ }^{\circ} \mathrm{C}$, water cluster grows across the pore, forming a bridge which prevents water molecules entering the pore interior. We will investigate this unusual behavior with other water models and different configurations of functional group, and will present the results in a future communication. 


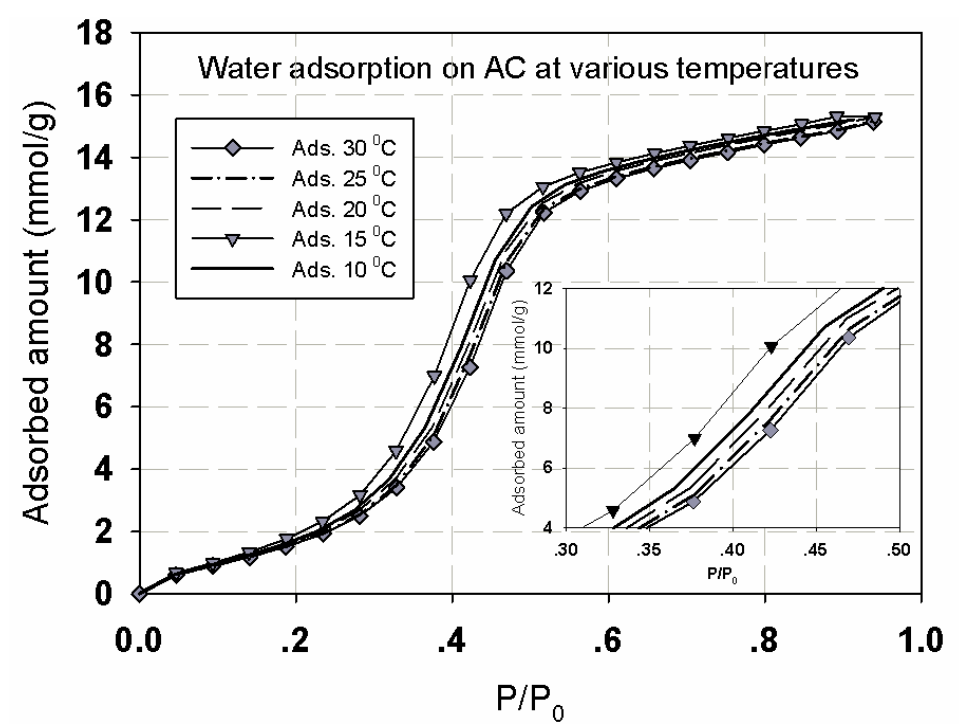

Fig. 18 The experimental data of water adsorption in unmodified activated carbon (ACC) at $30{ }^{\circ} \mathrm{C}$ (diamond symbols with solid line), $25^{\circ} \mathrm{C}$ (line and dotted), $20^{\circ} \mathrm{C}$ (dashed line), $15^{\circ} \mathrm{C}$ (triangle symbols with solid line) and $10^{\circ} \mathrm{C}$ (solid line).
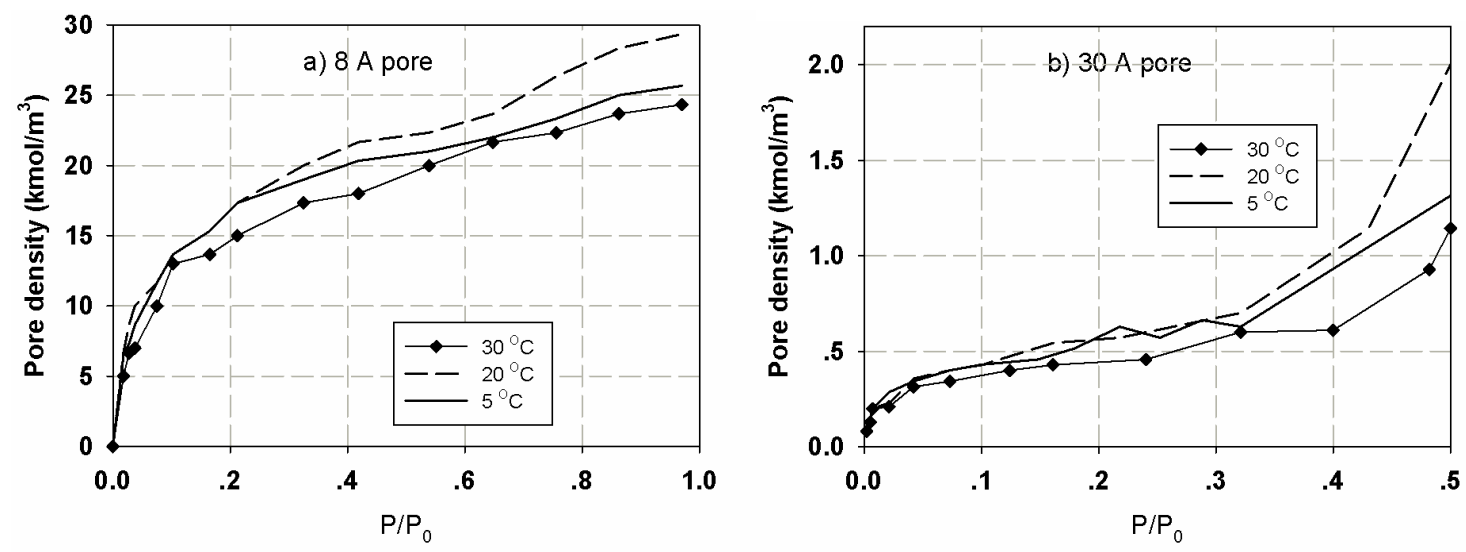

Fig. 19 The simulation isotherms of SPCE water adsorption in slit pore of $8 \AA$ (a) and $30 \AA$ (b) at $30^{\circ} \mathrm{C}$ (diamond symbols with solid line), $20^{\circ} \mathrm{C}$ (dashed line) and $5^{\circ} \mathrm{C}$ (solid line).

\section{Conclusion}

In this paper, we have presented the adsorption of water in activated carbons and carbon nanotubes with functional group grafted on the surfaces and studied the effects of functional group on the adsorption isotherm using a GCMC simulation. The simulation results show that the onset of adsorption and the porefilling occur at lower pressure with an increase in the functional group concentration. We also showed that the comparison between the simulation results and water adsorption isotherms at $298 \mathrm{~K}$ suggests that water adsorption at ambient temperatures could be used as an alternative to nitrogen adsorption at $77 \mathrm{~K}$ to characterize porous carbons for their microporosity. One interesting feature that arises from both experimental measurements and simulation is the unusual lower water adsorption capacity at low temperatures, and this is a subject of extensive investigation and results will be reported in due course.

\section{Acknowledgements}

This project is supported by Suranaree University of Technology under the grant number $8 / 2552$. We also acknowledge University of Queensland, Khon Kaen University and Nanyang Technological University for some experimental works. 


\section{References}

[1] D. Frenkel, and B. Smit, Understanding Molecular Simulation, $2^{\text {nd }}$ ed., New York, Academic Press, 2002.

[2] M. P. Allen and D. J. Tildesley:, Computer Simulation of Liquids, New York, Oxford Science Publications, 1987.

[3] D. D. Do, and H. D. Do, "Refined method of potential enhancement in the equilibria characterization of activated carbon: comparison with gcme and dft," Langmuir, vol. 19, no. 20, pp. 8302-15, 2003.

[4] E. A. Muller, L. F. Rull, L. F. Vega, and K. E. Gubbins, "Adsorption of water on activated carbons: a molecular simulation study," J. Phys. Chem., vol. 100, no. 4, pp. 1189-96, 1996.

[5] C. L. McCallum, T. J. Bandosz, S. C. McGrother, E. A. Muller, and K. E. Gubbins, "A molecular model for adsorption of waterr on activated carbon: comparison of simulation and experiment," Langmuir, vol. 15, no. 2, pp. 533-44, 1999.

[6] A. Striolo, A. A. Chialvo, P. T. Cummings, and K. E. Gubbins, "Water adsorption in carbon-slit nanopores," Langmuir, vol. 19, No. 20, pp. 8583-91, 2003.

[7] A. Striolo, K. E. Gubbins, A. A. Chialvo, and P. T. Cummings, "Simulated water adsorption isotherms in carbon nanopores," Molecular Physics, vol. 102, no. 3, pp. 243-251, 2004.

[8] M. Maddox, D. Ulberg, and K. E. Gubbins, "Molecular simulation of simple fluids and water in porous carbons," Fluid Phase Equilibria, vol. 104, pp. 145-58, 1995.

[9] R. E. Franklin, "Crystallite growth in graphitizing and non-graphitizing carbons," Proceeding of the Royal Society of London series A, Mathematical and Physical Sciences, vol. 209, no. 1097, pp. 196-218, 1951.

[10] A. Wongkoblap, and D. D. Do, "The effects of energy sites on adsorption of Lennard-Jones fluids and phase transition in carbon slit pore of finite length a computer simulation study," J. of Colloid and Interface Sci., vol. 297, no. 1, pp. 1-9, 2006.

[11] A. Wongkoblap, W. Intomya, W. Somrup, S. Charoensuk, S. Junpirom, and C. Tangsathitkulchai, "Pore size distribution of carbon with different probe molecules," Engineering Journal, vol. 14, no. 3, pp. 45-56, 2010.

[12] J. Jagiello, and J. Olivier, "2D-NLDFT adsorption models for carbon slit-shaped pores with surface energetical heterogeneity and geometrical corrugation," Carbon, vol. 55, pp. 70-80, 2013.

[13] D. D. Do, Adsorption Analysis: Equilibria and Kinetics, New Jersey, Imperial College Press, 1998.

[14] A. Wongkoblap, and D. D. Do, "The effects of curvature and surface heterogeneity on the adsorption of water in finite length carbon nanopores: a computer simulation study," Molecular Physics, vol. 106, no. 5, pp. 627-41, 2008.

[15] S. Iijima, "Helical microtubules of graphitic carbon," Nature, vol. 354, pp. 56-8, 1991.

[16] S. Agnihotri, J. P. B. Mota, M. Rostam-Abadi, and M. J. Rood, "Adsorption site analysis of impurity embedded single-walled carbon nanotube bundles," Carbon, vol. 44, no. 12, pp. 2376-83, 2006.

[17]J. C. Palmer, J. D. Moore, T. J. Roussel, J. K. Brennan, and K. E. Gubbins, "Adsorptive behavior of $\mathrm{CO}_{2}, \mathrm{CH}_{4}$ and their mixtures in carbon nanospace: A molecular simulation study," Physical Chemistry Chemical Physics, vol. 13, no. 9, pp. 3985-96, 2011.

[18] K. Murata, K. Kaneko, W. A. Steele, F. Kokai, K. Takahashi, D. Kasuya, K. Hirahara, M. Yudasaka, and S. Iijima, "Molecular potential structures of heat-treated single-wall carbon nanohorn assemblies," J. Phys. Chem. B, vol. 105, no. 42, pp. 10210-16, 2001.

[19] A. Wongkoblap, D. D. Do, and K. Wang, "Adsorption of polar and non polar fluids in carbon nanotube bundles: computer simulation and experimental studies," J. Colloid and Interface Sci., vol. 331, pp. 65-76, 2009.

[20] A. Striolo, A. A. Chialvo, P. T. Cummings, and K. E. Gubbins, "Simulated water adsorption in chemically heterogeneous carbon nanotubes," J. of Chem. Phys., vol. 124, no. 7, art. no. 074710, 2006.

[21] G. R. Birkett, and D. D. Do, "The adsorption of water in finite carbon pores," Molecular Phys., vol. 104, no. 4, pp. 623-37, 2006.

[22] A. Wongkoblap, and D. D. Do, "Adsorption of water in finite length carbon slit pore: comparison between computer simulation and experiment," J. Phys. Chem. B, vol. 111, no. 50, pp. 13949-56, 2007.

[23]J. C. Liu, and P. A. Monson, "Does water condense in carbon pores?," Langmuir, vol. 21, mo. 22, pp. 10219-25, 2005.

[24]J. C. Palmer, J. D. Moore, J. K. Brennan, and K. E. Gubbins, "Simulating local adsorption isotherms in structurally complex porous materials: A direct assessment of the slit pore model," J. of Physical Chemistry Letters, vol. 2, no. 3, pp. 165-9, 2011. 
[25] H. J. C. Berendsen, J. P. M. Postma, W. F. van Gunsteren, and J. Hermans, in B. Pullman (Ed.), Intermolecular Forces, Reidel, Dordrecht, the Netherlands, vol. 331, 1981.

[26] H. J. C. Berendsen, J. R. Grigera, and T. P. Straatsma, "The missing term in effective pair potentials," J. Phys. Chem., vol. 91, no. 24, pp. 6269-71, 1987.

[27] F. H. Stillinger, and A. Rahman, J. of Chem. Phys., vol. 60, pp. 1545-57, 1974.

[28]J. Slovak, and I. Nezbeda, "Extended five-site primitive models of water: Theory and computer simulations," Molecular Physics, vol. 91, no. 6, pp. 1125-36, 1997.

[29] T. Horikawa, N. Sakao, and D. D. Do, "Effects of temperature on water adsorption on controlled microporous and mesoporous carbonaceous solids," Carbon, Article in press, 2013.

[30] S. Brunauer, L.S. Deming, W. E. Deming, and E. J. Teller, J. Am. Chem. Soc., vol. 62, pp. 1723, 1940.

[31] S. Junpirom, C. Tangsathitkulchai, M. Tangsathitkulchai, and Y. Ngernyen, "Water adsorption in activated carbons with different burn-offs and its analysis using a cluster model," Korean J. Chem. Eng., vol. 25, no. 4, pp. 825-32, 2008.

[32] E. A. Muller, F. R. Hung, and K. E. Gubbins, "Adsorption of water vapor-methane mixtures on activated carbons," Langmuir, vol. 16, no. 12, pp. 5418-24, 2000.

[33] H. P. Boehm, "Surface oxides on carbon and their analysis: a critical assessment," Carbon, vol. 40, no. 2, pp. 145-9, 2002.

[34] Y. Maniwa, H. Kataura, M. Abe, A. Udaka, S. Suzuki, Y. Achiba, H. Kira, K. Matsud, H. Kadowaki, and Y. Okabe, "Ordered water inside carbon nanotubes: Formation of pentagonal to octagonal icenanotubes," Chem. Phys. Lett., vol. 401, no. 4-6, pp. 534-8, 2005.

[35] K. Miura, and T. Morimoto, "Adsorption sites for waterr on graphite. 6. effect of ozone treatment of sample," Langmuir, vol. 10, pp. 807-11, 1994.

[36] C. Tangsathitkulchai, Y. Ngernyen, and M. Tangsathitkulchai, "Surface modification and adsorption of eucalyptus wood-based activated carbons: Effects of oxidation treatment, carbon porous structure and activation method," Korean J. Chem. Eng., vol. 26, no. 5, pp. 1341-52, 2009.

[37] Online at http://www.cheaptubesinc.com/applications.htm 
